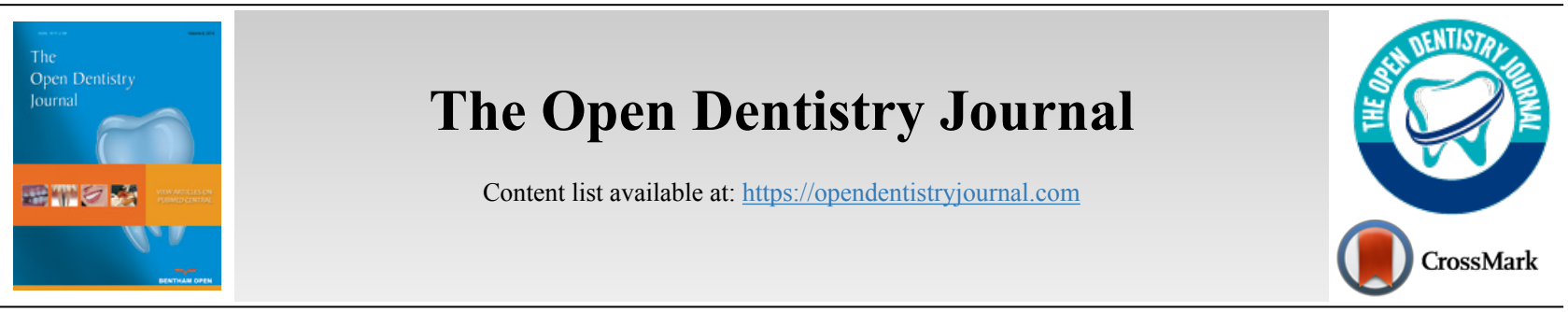

RESEARCH ARTICLE

\title{
Porous Titanium Granules for Sinus Floor Augmentation: A Case Series Study
}

\author{
Hamid Reza Arab ${ }^{1}$, Hamid Reza Boostani ${ }^{2}$, Amir Moeintaghavi ${ }^{3, *}$ and Farid Shiezadeh ${ }^{1, *}$ \\ ${ }^{\prime}$ Dental Research Center, Mashhad University of Medical Sciences, Mashhad, Iran \\ ${ }^{2}$ Private Practice Periodontist, Tehran, Iran \\ ${ }^{3}$ Oral and Maxillofacial Diseases Research Center, Mashhad University of Medical Sciences, Mashhad, Iran
}

\begin{abstract}
:
Background:

Sinus grafting with autogenous bone and other bone substitutes has been shown to be a safe technique with high predictability of success, but it has not been determined which of these materials provide better osteogenic potential. The aim of the present study was to clinically and radiographically evaluate the use of $\mathrm{Natix}^{\mathrm{TM}}$ grafting material in maxillary sinus elevation procedures with simultaneous implant placement in humans.

\section{Materials and Methods:}

Fifteen patients ( 6 women and 9 men) requiring augmentation of the maxillary sinus before implant placement were voluntarily enrolled in this study. After the sinus graft procedure, a bone augmentation material of porous titanium granules (Natix ${ }^{\mathrm{TM}}$, TigranTecnologies, Malmö, Sweden) was placed into the sinus cavity. The primary stability of the fixtures was measured at baseline and 6 months following the implantation. Panoramic x-rays for objective measurements of bone height at the floor of sinus were repeated at 18 months, and 36 months postoperatively.

\section{Results:}

The 15 patients had in total 20 implants installed. Panoramic radiographs made 6 months post-insertion showed a radio-opaque area around the implants.Also at 6 months post-placement, all 18 implants were clinically stable and abutments were connected. Bone biopsies were taken from 1 grafted site in 1 patient. Excluding the one implant failing to achieve primary stability at baseline, the cumulative implant survival rate in this pilot study was $94.7 \%$.

\section{Conclusion:}

The results of the study showed that maxillary sinus augmentation with porous titanium granules provided predictable survival of implants in 36 months.

Keywords: Sinus floor augmentation, Guided bone regeneration, Porous titanium granule, Alveolar crest, Dental implants, Maxillary atrophy.

\begin{tabular}{l|l|l|l} 
Article History & Received: June 09, 2019 & Revised: August 26, 2019 & Accepted: October 10, 2019
\end{tabular}

\section{INTRODUCTION}

Resorption of the alveolar crest following tooth loss, resulting in atrophy of the alveolar process in the posterior parts of the maxilla, is a condition that may restrict implant placement in such areas. Maxillary sinus augmentation procedures, before or at the time of placement of dental implants, are a well-established technique for rehabilitation of partially or completely edentulous patients with severe maxillary atrophy.

\footnotetext{
* Address correspondence to this author at Oral and Maxillofacial Diseases Research Center, Mashhad University of Medical Sciences, Mashhad, Iran; Tel: 0098511 6012189; Fax: 0098511 8829500;

E-mails: Moeentaghavia@mums.ac.ir ; shiezadehfr@mums.ac.ir
}

Bone grafts and bone graft substitutes have been used, allowing the placement of implants of adequate length and width in the posterior maxillary region [1].

Sinus grafting with autogenous bone and other bone substitutes have been shown to be a safe technique with high predictability of success, but it is not established, which of these materials provide better osteogenic potential and biomechanical properties [2 - 4]. Various bone grafting materials have been used in sinus augmentation, such as autogenous grafts $[2,5]$, freeze-dried bone allografts [6], hydroxyapatite [7, $8]$, and xenografts $[9,10]$.

Autogenous bone is the material of choice for bone 
augmentation procedures [2, 7]. However, its use can be restricted because of the following problems: Donor site morbidity; limited amounts of graft material that can be harvested intraorally; and fast resorption of grafts which makes it difficult to keep space under the sinus membrane [11].

Therefore, bone substitutes have been used to avoid the graft-harvesting procedure. They are all resorbable, although resorbing very slowly. A material that is completely resistant to resorption and has good clotting properties seems so suitable especially for reconstruction of moderate and large defects. Titanium granules are particles consisting of irregular and porous granules of commercially pure titanium, therefore, they lead to ingrowth of the newly formed bone. The results have been very promising when tested in orthopedic surgery for fixation of femoral stems. Clinical and experimental histological studies have shown bone formation in and around the granules [12, 13].

It is clear that stability, both at placement and during function, is an important criterion for the success of dental implants, therefore, we need a clinical tool to evaluate dental implant stability prior to loading, especially for implants placed in the maxilla [14]. Low failure rates were reported when a minimum stability level was used as an inclusion criterion for immediate loading in totally edentulous maxillae and in posterior mandibles [15]. Quantitative methods, including resonance frequency analysis, can yield valuable information [16].

The aim of the present study was to clinically and radiographically evaluate the use of Natix ${ }^{\mathrm{TM}}$ grafting material in maxillary sinus elevation procedures with a simultaneous implant placement in humans. It was also aimed to document the short-term clinical success of fixtures inserted in the sinus cavities augmented with Natix ${ }^{\mathrm{TM}}$.

\section{MATERIALS AND METHODS}

\subsection{Patients}

The Institutional Review Board at the Mashhad University of Medical Sciences, Mashhad, Iran approved the study. No animals were used in this research. All the research procedures followed were in accordance with the ethical standards of the committee responsible for human experimentation (The Institutional Ethical Committee of Mashhad University of Medical Sciences, Mashhad, Iran), and with the Helsinki Declaration of 1975, as revised in 2008 .

The participants provided written informed consent for involvement in this study. The study was performed between 2013 and 2015. Fifteen patients (6 women and 9 men, mean age of 58 years, ranging 40-68 years) in need for augmentation of the maxillary sinus before implant placement were enrolled. As a criterion for involvement in the study, the patients were required to have unilateral and bilateral edentulous maxillary premolar/molar areas. The lack of any pathology or septa which might interfere with the operation was verified on CBCT radiographs prior to planning. The distance from the alveolar crest to the sinus floor was required to be in the range of 2-6 $\mathrm{mm}$ measured using panoramic radiographs (PM2002CC, Planmeca, Helsinki, Finland) on preoperative radiographs (Fig. 1).
Patients with the pathology of the maxillary sinus, smokers or patients with systemic contraindications to surgical procedures were not included in the study.

\subsection{Sinus Augmentation Technique}

Before the surgical procedure, the patients were asked to rinse their mouth with a $0.2 \%$ chlorhexidine digluconate solution for 1 minute. Following the administration of local anesthesia (2\% lidocaine containing 1:80,000 epinephrine Daropakhsh, Iran), a horizontal anterior-posterior incision was made slightly palatal to the alveolar crest. Two buccal releasing incisions, at the anterior and posterior ends of the horizontal incision, were made. Full-thickness flaps were carefully elevated to expose the alveolar crest and the lateral sinus wall.

A 7-12 mm window on the lateral aspect of the sinus wall was prepared using a piezosurgery head (Mectron, Italy) with generous saline irrigation (Fig. 2). The inferior border of the osteotomy was situated approximately 3-4 $\mathrm{mm}$ apical to the sinus floor. The sinus membrane was carefully elevated using appropriate curettes. The sinus membrane was detached along the inferior distal and medial walls of the sinus. If perforation of the sinus membrane occurred during the procedure, a double layer of collagen membranes (T-Barrier, B \& B Dental, Pietro, Italy) was used to ensure stabilization of graft material. A bone augmentation material of porous titanium granules (Natix ${ }^{\mathrm{TM}}$, Tigran-Tecnologies, Malmö, Sweden) was mixed with blood and normal saline solution (Fig. 3) and placed into the sinus cavity (Fig. 4). Following graft placement at the medial aspect of the cavity, $12 \mathrm{~mm}$ implants (BioHorizons Birmingham, AL, USA) were placed, followed by overlying of some more graft materials until filled. The density and amount of filling were determined so as to obtain the complete coverage of the implant surface. The osteotomy window was then covered with another piece of the collagen membrane. Cover screws were placed on implants and the flaps sutured using 4-0 vicryl sutures (Supa, Iran). The patients were administered $1 \mathrm{~g}$ amoxicillin 1 hour before the operation and then $500 \mathrm{mg}$ three times per day for 7 days. The sutures were removed 2 weeks following surgery.

Patients were treated in a one-stage procedure .The reason for choosing a two-stage procedure was the lack of initial implant stability. In the two-stage procedure, the augmentation was performed 6 months before implant installation. At that time, when possible, vertically, bone cores were harvested from the crest area of the alveolar ridge using a $2 \mathrm{~mm}$ diameter trephine under abundant saline irrigation before site preparation for an implant. The cores were obtained to a mean depth of $10 \mathrm{~mm}$.

\subsection{Measurements}

The primary stability of the fixtures was measured using a resonance frequency device (Osstell Mentor, Gothenburg, Sweden) at baseline and 6 months following the implantation (Fig. 5). 


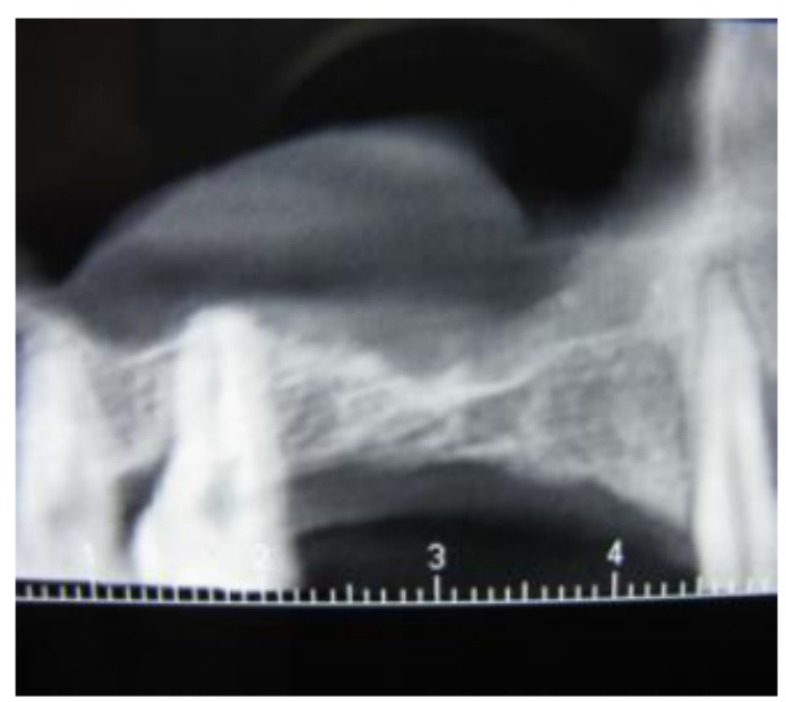

Fig. (1). Bone height at base line in pre operative radiography.

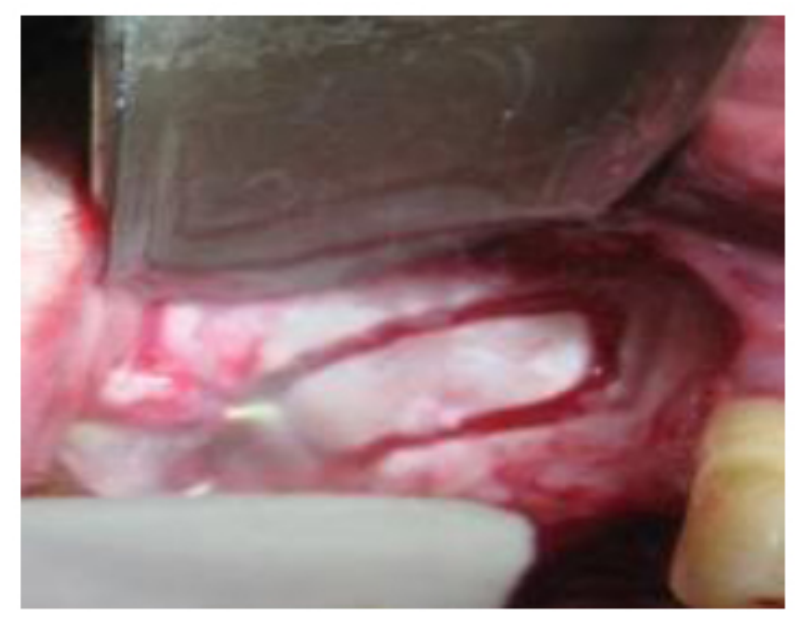

Fig. (2). Oval-shaped osteotomy on the lateral aspect of the sinus wall.

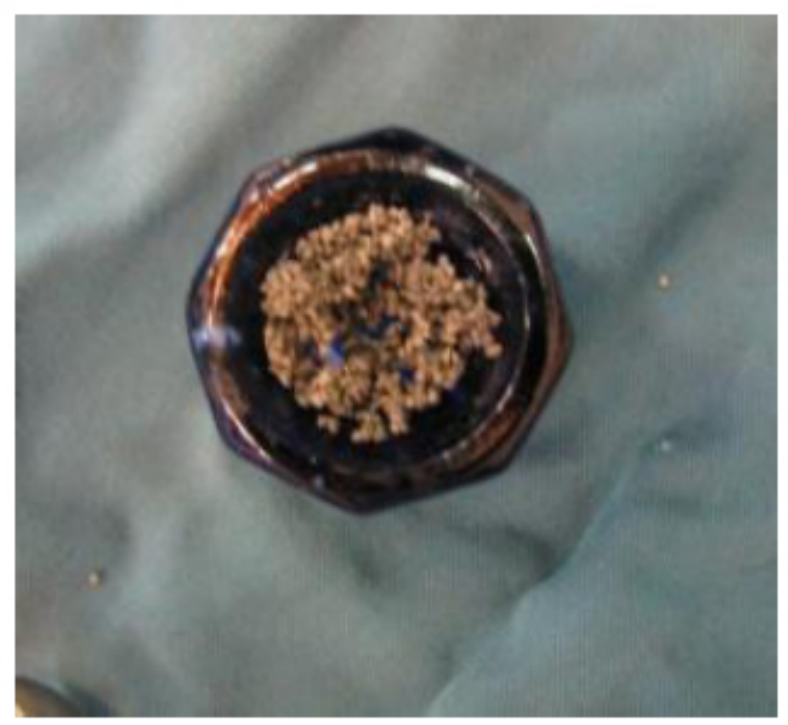

Fig. (3). Natix granules mixed with blood and normal saline.

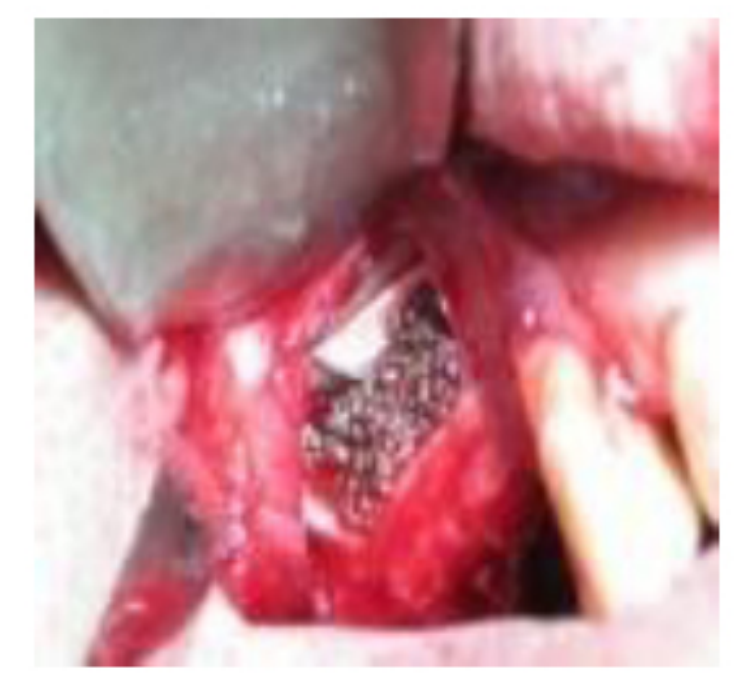

Fig. (4). Placement of granules inside the sinus.

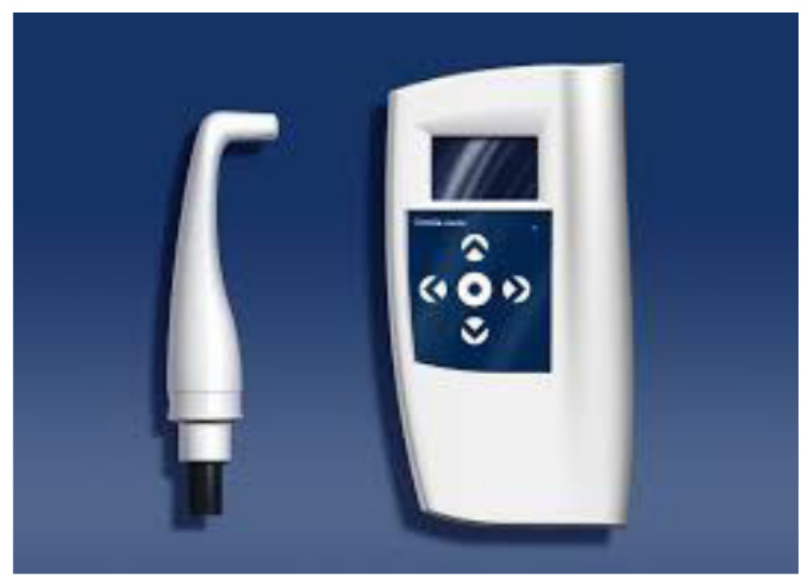

Fig. (5). Ostell mentor.

The patients were clinically examined monthly for followup. After augmentation, the first panoramic radiograph was taken at 6 months time-point. The second stage surgery was carried out, and the ISQ levels were measured as described above. The healing abutments were connected to the implants. Implants with ISQ (Implant Stability Quotient) levels greater than 60 were preceded to prosthetic fabrication. Panoramic $\mathrm{x}$ rays for qualitative assessment of grafted sinus as well as objective measurements of bone height at the floor of sinus were repeated at 18 months, and 36 months postoperatively (Fig. 6).

The methods proposed by Naoki Hatano et al. (2004) were used to assess digital panoramic $\mathrm{x}$-rays. Using manual tracing, the fixture, ridge crest, original sinus floor, and grafted sinus floor (distance from the top of the bone-to-implant contact region to the grafted sinus floor) were drawn on a tracing paper by overlying the radiographs using a soft pencil (Fig. 7). X rays were exposed at $68 \mathrm{kvp}, 10 \mathrm{~mA}$, and 16 seconds and this was consistent throughout the study period. All the radiographs were evaluated by a blinded dentist trained in evaluating panoramics. To calculate the measurement reproducibility, 5 randomly selected study films (each containing 5 radiographic 
study sites) were assessed. The examiner repeated the measurements after one week with a different order. The measurements proved to be within $1 \mathrm{~mm}$ at $96 \%$ of the occasions.

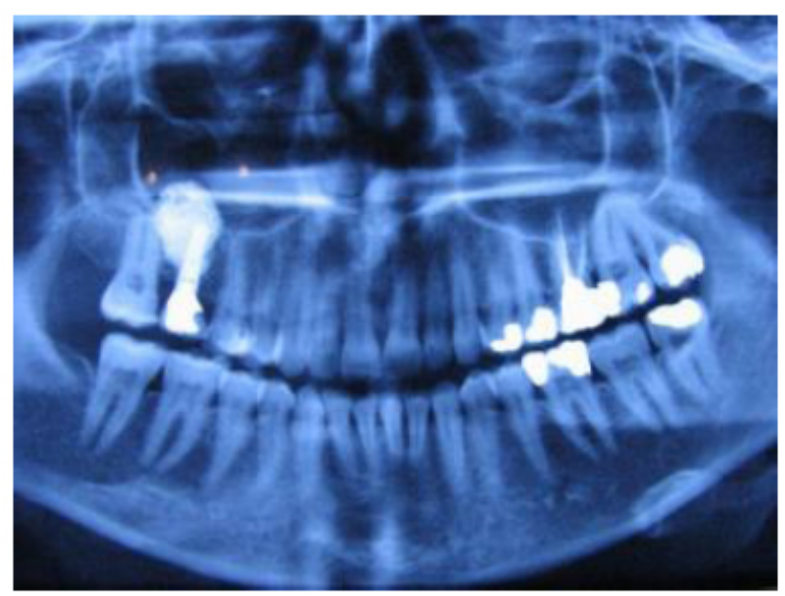

Fig. (6). Panoramic x-rays for qualitative assessment of grafted sinus 18 months, and 36 months post operatively.

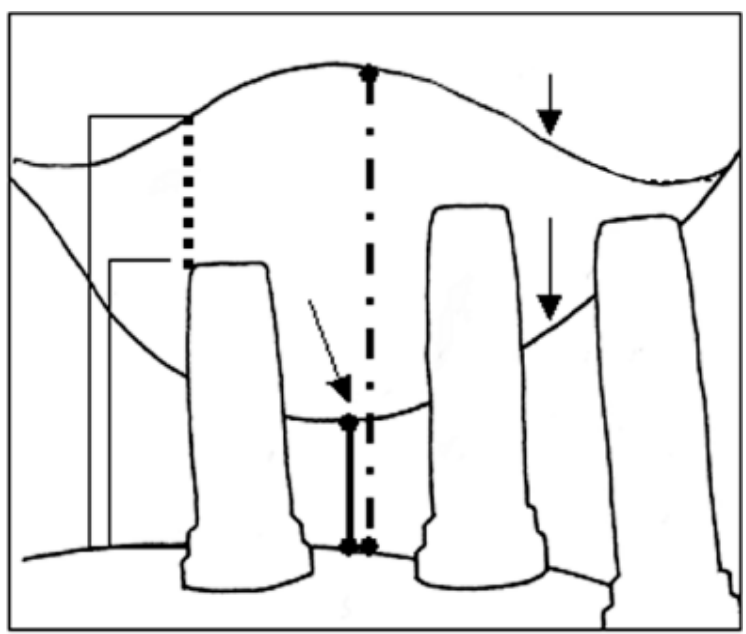

Fig. (7). By manual tracing, the fixture, ridge crest, original sinus floor, and grafted sinus was drawn on tracing paper by overlying the radiographs using a soft pencil.

\subsection{Statistical Analysis}

All the study data including baseline and 6 month ISQ values as well as primary and secondary bone heights were expressed as mean and standard deviation. Data were analyzed using a statistical program software (SPSS, version 13, Chicago, IL, USA) to evaluate the differences over time in frequency resonance measurements (ISQ values). Changes in graft volume at different time intervals were analyzed using paired t-test.The level of statistical significance was defined as $P<0.05$. Pearson correlation coefficients were used to assess the relationship between ISQ levels and bone heights at baseline as well as at six months.

\section{RESULTS}

Table 1 summarizes the data of all the subjects. The 15 patients had in total 20 implants installed. In one implant of one of the patients (patient 5), we could not observe primary stability, and therefore, it was treated in two separate operations. The reason for choosing a two-stage procedure was the lack of initial implant stability. In the two-stage procedure, the augmentation was performed 6 months before implant installation. Bone biopsies were taken from 1 grafted site in 1 patient. We observed that after 6 months, there were signs of new bone formation around Porous Titanium Granules particles. Most of the newly formed bone was lamellar bone, and there were little loose connective tissues filling the space between the particles. The percentage of bone formation in this specimen was $22 \%$. A titanium granule that partially filled with new bone was observed (Fig. 8).

In another instance (patient 4), the sinus mucosa was perforated during surgery and managed with the double layers of collagen membrane to seal. Finally, for another patient (patient 13), excessive bleeding occurred during surgery due to the perforation of the posterior superior alveolar artery. The bleeding was controlled by a homeostatic sponge (Gelotamp, Coltene, Switzerland) but the implant placed there was found to be mobile, one month after surgery and removed. None of the other patients demonstrated postoperative complications or infections other than normal postoperative swelling at the surgical sites.

Panoramic radiographs made 6 months post-insertion showed a radio-opaque area around the implants (Fig. 6). Also, at 6 months post-placement, all 18 implants were clinically stable and abutments were connected. After 6 months, all the implants had ISQ levels greater 60 (Table 1). In all cases, the grafted sinus floor was above the implant apex.

On the radiographs taken 18 and 36 months after graft placement (Fig. 7), no signs of migration or loss of the titanium granules were seen. Furthermore, no implants were lost or found to be unstable up to 36 months following implantation. Excluding the one implant failing to achieve primary stability at baseline, the cumulative implant survival rate in this pilot study was $94.7 \%$.

The mean ISQ at baseline and after 6 months was $52.83 \pm 6.82$ and $70 \pm 7.73$ respectively $(p=0.000)$. The mean primary and secondary height of bone were $4.26 \pm 1.19 \mathrm{~mm}$ and $14.63 \pm 1.16 \mathrm{~mm}$, respectively $(p=0.000)$. There was no correlation between the baseline and primary height of bone. Moreover, there was no significant correlation between 6month ISQ and the secondary height of bone. Finally, the ISQ levels at baseline and 6 months showed no significant correlation.

\section{DISCUSSION}

This study assessed the performance of porous titanium granules in one-stage sinus augmentation with simultaneous implant placement in patients with 2-6 $\mathrm{mm}$ of residual bone height prior to sinus grafting. It was shown that titanium granules seemed to work suitably as bone graft material in the sinus lift procedure, even when the fixture installation and augmentation were performed simultaneously. The implant survival rate in this pilot study was high and acceptable (94.7\%). 
Table 1. Praimary and secondary heights of bone at baseline and after 6 months. ISQ1 and ISQ2 have been also included.

\begin{tabular}{|c|c|c|c|c|c|c|c|c|c|}
\hline Patient & Gender & $\begin{array}{c}\begin{array}{c}\text { Age } \\
\text { (years) }\end{array} \\
\end{array}$ & Primary Height & $\begin{array}{c}\text { Height at } 6 \\
\text { Months }\end{array}$ & ISQ1 & ISQ2 & \begin{tabular}{|l|}
$\begin{array}{c}\text { Complication During } \\
\text { and after Operation }\end{array}$ \\
\end{tabular} & \begin{tabular}{c|} 
Complication at \\
18 and 36 Month \\
\end{tabular} & Implant Size \\
\hline 1 & Female & 62 & $\begin{array}{l}\text { T } 5: 5 \mathrm{~mm} \\
\text { T } 6: 4 \mathrm{~mm}\end{array}$ & $\begin{array}{l}13 \mathrm{~mm} \\
16 \mathrm{~mm}\end{array}$ & $\begin{array}{l}50 \\
61\end{array}$ & $\begin{array}{l}68 \\
71\end{array}$ & - & - & $\begin{array}{l}4.12 \\
4.12\end{array}$ \\
\hline 2 & Male & 40 & T $6: 5 \mathrm{~mm}$ & $15 \mathrm{~mm}$ & 53 & 80 & - & - & 4.12 \\
\hline 3 & Female & 68 & $\begin{array}{l}\text { T } 5: 6 \mathrm{~mm} \\
\text { T6: } 3 \mathrm{~mm}\end{array}$ & $\begin{array}{l}17 \mathrm{~mm} \\
15 \mathrm{~mm}\end{array}$ & $\begin{array}{l}42 \\
50\end{array}$ & $\begin{array}{l}58 \\
61\end{array}$ & - & - & $\begin{array}{l}4.12 \\
5.12\end{array}$ \\
\hline 4 & Male & 68 & T $6: 3 \mathrm{~mm}$ & $13 \mathrm{~mm}$ & 53 & 72 & Membrane perforation & - & 4.12 \\
\hline 5 & Male & 54 & $\begin{array}{c}\text { Lack of initial stability } \\
\text { T } 6: 3 \mathrm{~mm}\end{array}$ & $16 \mathrm{~mm}$ & 47 & 72 & - & - & 4.12 \\
\hline 6 & Female & 53 & $\mathrm{~T} 5: 5 \mathrm{~mm}$ & $15 \mathrm{~mm}$ & 41 & 58 & - & - & 4.12 \\
\hline 7 & Male & 62 & $\begin{array}{l}\text { T5: } 3 \mathrm{~mm} \\
\text { T6:6mm }\end{array}$ & $\begin{array}{l}14 \mathrm{~mm} \\
13 \mathrm{~mm}\end{array}$ & $\begin{array}{l}50 \\
52\end{array}$ & $\begin{array}{l}70 \\
70\end{array}$ & - & - & $\begin{array}{c}3.5 .12 \\
4.12\end{array}$ \\
\hline 8 & Female & 50 & $\mathrm{~T} 6: 2 \mathrm{~mm}$ & $15 \mathrm{~mm}$ & 58 & 92 & - & - & 4.12 \\
\hline 9 & Male & 62 & $\mathrm{~T} 6: 5 \mathrm{~mm}$ & $16 \mathrm{~mm}$ & 62 & 72 & - & - & 4.12 \\
\hline 10 & Male & 57 & T6:4mm & $13 \mathrm{~mm}$ & 58 & 72 & - & - & 4.12 \\
\hline 11 & Male & 52 & $\mathrm{~T} 6: 3 \mathrm{~mm}$ & $15 \mathrm{~mm}$ & 55 & 70 & - & - & 4.12 \\
\hline 12 & Male & 66 & $\mathrm{~T} 6: 4 \mathrm{~mm}$ & $14 \mathrm{~mm}$ & 52 & 64 & - & - & 4.12 \\
\hline 13 & Female & 67 & $\mathrm{~T} 6: 6 \mathrm{~mm}$ & $15 \mathrm{~mm}$ & 50 & $\begin{array}{l}\text { Mobiliy after } \\
\text { 1month }\end{array}$ & Hemorrhagic event & - & 4.12 \\
\hline 14 & Male & 53 & $\mathrm{~T} 6: 5 \mathrm{~mm}$ & $14 \mathrm{~mm}$ & 67 & 72 & - & - & 4.12 \\
\hline 15 & Female & 57 & $\begin{array}{l}\mathrm{T} 6: 4 \mathrm{~mm} \\
\mathrm{~T} 7: 5 \mathrm{~mm}\end{array}$ & $\begin{array}{l}15 \mathrm{~mm} \\
14 \mathrm{~mm}\end{array}$ & $\begin{array}{l}45 \\
55\end{array}$ & $\begin{array}{l}68 \\
70\end{array}$ & - & - & $\begin{array}{l}4.12 \\
5.12\end{array}$ \\
\hline
\end{tabular}

Several studies have recommended the 2-step procedure in patients with less than $5 \mathrm{~mm}$ of alveolar bone height in the posterior maxilla [17]. The results of our investigation suggest that porous titanium granules, in 1 stage procedure, and even in $2 \mathrm{~mm}$ residual bone height, support adequate bone quality for predictable simultaneous implant placement [18]. It has been observed that the single-step procedure is feasible even for patients with as little as $3 \mathrm{~mm}$ of primary alveolar bone height, using hydroxyapatite-coated implants and autogenous bone. The most important advantages of the 1-step procedure are reducing the number of surgical procedures and the time needed to deliver the implant-supported prosthesis to patients. However, it is not clear if this material can be used safely and predictably for two-stage procedures. One implant fixtures were lost, maybe because of homeostatic spongy material which was used for controlling the hemorrhage from cutting the intra alveolar artery and its interaction with wound healing.

In spite of findings in the literature indicating that autogenous bone grafts are superior to allogenic and alloplastic materials [19], in some other studies, resorption rate of up to $55 \%$ during the first 6 months has been reported [20]. So extensive resorption of the grafting material makes the treatment results difficult to predict.The non-resorbable materials such as Natix are resistant to resorption and therefore, would be able to maintain the graft volume. Although it is difficult to determine the exact border of the sinus membrane and the Natix in radiographs, but a regular radiographic examination in this study showed there were no changes at these sites even 36 months after grafting. In other words, the fact that titanium granules do not resorb indicates that they may act as a mechanical barrier i.e. granules may prevent new bone from reaching the dental implant surface. However, Turner and colleagues claimed in their histological study that this does not seem to be true, maybe because of the porosity properties of titanium granules [13].

Also Bystedt confirmed, in histological examination of the biopsy specimens, the osteoconductive properties of Natix, by showing the close contact between this material and the newly formed bone and bone growth along the scaffold of the particles, but he concluded that 6 months is probably a very short time-period before fixture installation because he reported that the formation of the new bone around the titanium granules used in his study took longer and utilized HidroxyApatite particles [21]. Turner et al. showed bone formation within and around the granules but the granules were used in the femur in a dog model and were not comparable with the granules in the human sinus [13].

Dursun et al. [22] in a pilot clinical trial study analyzed the bone microarchitecture at augmented maxillary sinus sites by using different materials in patients to compare the effect of porous titanium granules as a sinus augmentation material. No statistically significant differences were found between materials according to bone structural parameters.

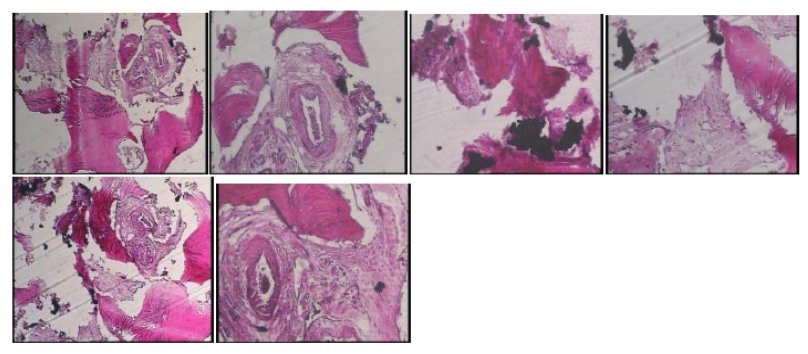

Fig. (8). Histologic section of grafted sinus shows new bone formation around Porous Titanium Granules. 
It was concluded that porous titanium grafts ensure a space for new bone formation in the granules, which may be a clinical advantage for long-term success [22].

Verket et al. in their clinical study assessed bone ingrowth into porous titanium granules used for maxillary sinus augmentation. After 6 months, they observed that the new bone formed at a similar rate and of the same quality with the other well-known graft materials. Moreover, the size of the new bone was $16 \%$ similar to the present study with $22 \%$ new bone formation [23]

The results of the study indicate that titanium granules are suitable for a one-stage sinus lift procedure. However, it is not yet clear whether these granules lend themselves as easily in a tow-stage procedure. Bone formation might be difficult where titanium granules have been incorporated. Furthermore, preparing such bone may give rise to high temperatures at the surgical site. These concerns warrant further investigations.

\section{CONCLUSION}

In conclusion, the results of our study showed that maxillary sinus augmentation with porous titanium granules provided predictable survival of implants in 36 months.

\section{ETHICS APPROVAL AND CONSENT TO PARTI- CIPATE}

The study was approved by the Ethics Committee of Mashhad University of Medical Sciences, Iran with number: IR 98/296717.

\section{HUMAN AND ANIMAL RIGHTS}

No animals were used in this research. All research procedures were followed in accordance with the ethical standards of the committee responsible for human experimentation (institutional and national), and with the Helsinki Declaration of 1975, as revised in 2013. (http://ethics.iit.edu/ecodes/node/3931).

\section{CONSENT FOR PUBLICATION}

The participants provided written informed consent to be involved in this study.

\section{AVAILABILITY OF DATA AND MATERIALS}

The data supporting the findings of the article is available at the Mashhad University of Medical Sciences Clinical Data registration center: 98-296717.

\section{FUNDING}

None.

\section{CONFLICT OF INTEREST}

The authors declare no conflict of interest, financial or otherwise.

\section{ACKNOWLEDGEMENTS}

Declared none.

\section{REFERENCES}

[1] Hallman M, Hedin M, Sennerby L, Lundgren S. A prospective 1-year clinical and radiographic study of implants placed after maxillary sinus floor augmentation with bovine hydroxyapatite and autogenous bone. $\mathrm{J}$ Oral Maxillofac Surg 2002; 60(3): 277-84.

[http://dx.doi.org/10.1053/joms.2002.30576] [PMID: 11887139]

[2] Hirsch JM, Ericsson I. Maxillary sinus augmentation using mandibular bone grafts and simultaneous installation of implants. A surgical technique. Clin Oral Implants Res 1991; 2(2): 91-6.

[http://dx.doi.org/10.1034/j.1600-0501.1991.020207.x] [PMID: 1809404]

[3] Betts NJ, Miloro M. Modification of the sinus lift procedure for septa in the maxillary antrum. J Oral Maxillofac Surg 1994; 52(3): 332-3. [http://dx.doi.org/10.1016/0278-2391(94)90313-1] [PMID: 8308638]

[4] Hürzeler MB, Kirsch A, Ackermann KL, Quiñones CR. Reconstruction of the severely resorbed maxilla with dental implants in the augmented maxillary sinus: A 5-year clinical investigation. Int J Oral Maxillofac Implants 1996; 11(4): 466-75. [PMID: 8803342]

[5] Lundgren S, Moy P, Johansson C, Nilsson H. Augmentation of the maxillary sinus floor with particulated mandible: A histologic and histomorphometric study. Int J Oral Maxillofac Implants 1996; 11(6): 760-6.

[PMID: 8990638]

[6] Nishibori M, Betts NJ, Salama H, Listgarten MA. Short-term healing of autogenous and allogeneic bone grafts after sinus augmentation: A report of 2 cases. J Periodontol 1994; 65(10): 958-66.

[http://dx.doi.org/10.1902/jop.1994.65.10.958] [PMID: 7823278]

[7] Moy PK, Lundgren S, Holmes RE. Maxillary sinus augmentation: histomorphometric analysis of graft materials for maxillary sinus floor augmentation. J Oral Maxillofac Surg 1993; 51(8): 857-62. [http://dx.doi.org/10.1016/S0278-2391(10)80103-X]

[PMID: 8393101]

[8] Wheeler SL. Sinus augmentation for dental implants: the use of alloplastic materials. J Oral Maxillofac Surg 1997; 55(11): 1287-93. [http://dx.doi.org/10.1016/S0278-2391(97)90186-5] [PMID: 9371121]

[9] Smiler DG, Johnson PW, Lozada JL, et al. Sinus lift grafts and endosseous implants. Treatment of the atrophic posterior maxilla. Dental Clin North Am 1992; 36(1): 151-86. discussion 87-8.

[10] Valentini P, Abensur D. Maxillary sinus floor elevation for implant placement with demineralized freeze-dried bone and bovine bone (Bio-Oss): A clinical study of 20 patients. Int $\mathrm{J}$ Periodontics Restorative Dent 1997; 17(3): 232-41. [PMID: 9497715]

[11] Cordioli G, Mazzocco C, Schepers E, Brugnolo E, Majzoub Z. Maxillary sinus floor augmentation using bioactive glass granules and autogenous bone with simultaneous implant placement. Clinical and histological findings. Clin Oral Implants Res 2001; 12(3): 270-8. [http://dx.doi.org/10.1034/j.1600-0501.2001.012003270.x] [PMID: 11359485]

[12] Alffram PA, Bruce L, Bjursten LM, Urban RM, Andersson GB. Implantation of the femoral stem into a bed of titanium granules using vibration: A pilot study of a new method for prosthetic fixation in 5 patients followed for up to 15 years. Ups J Med Sci 2007; 112(2): 183-9.

[http://dx.doi.org/10.3109/2000-1967-192] [PMID: 17578818]

[13] Turner TM, Urban RM, Hall DJ, Andersson GB. Bone ingrowth through porous titanium granulate around a femoral stem: Histological assessment in a six-month canine hemiarthroplasty model. Ups J Med Sci 2007; 112(2): 191-7.

[http://dx.doi.org/10.3109/2000-1967-193] [PMID: 17578819]

[14] Ersanli S, Karabuda C, Beck F, Leblebicioglu B. Resonance frequency analysis of one-stage dental implant stability during the osseointegration period. J Periodontol 2005; 76(7): 1066-71.

[http://dx.doi.org/10.1902/jop.2005.76.7.1066] [PMID: 16018748]

[15] Ostman PO, Hellman M, Sennerby L. Direct implant loading in the edentulous maxilla using a bone density-adapted surgical protocol and primary implant stability criteria for inclusion. Clin Implant Dent Relat Res 2005; 7(Suppl. 1): S60-9.

[http://dx.doi.org/10.1111/j.1708-8208.2005.tb00076.x] [PMID: 16137089]

[16] Sennerby L, Meredith N. Implant stability measurements using resonance frequency analysis: biological and biomechanical aspects and clinical implications. Periodontol 2000 2008; 47: 51-66. [http://dx.doi.org/10.1111/j.1600-0757.2008.00267.x] [PMID: 18412573] 
[17] Raghoebar GM, Brouwer TJ, Reintsema H, Van Oort RP. Augmentation of the maxillary sinus floor with autogenous bone for the placement of endosseous implants: A preliminary report. J Oral Maxillofac Surg 1993; 51(11): 1198-203.

[http://dx.doi.org/10.1016/S0278-2391(10)80288-5] [PMID: 8229391]

[18] Peleg M, Mazor Z, Garg AK. Augmentation grafting of the maxillary sinus and simultaneous implant placement in patients with 3 to $5 \mathrm{~mm}$ of residual alveolar bone height. Int J Oral Maxillofac Implants 1999; 14(4): $549-56$

[PMID: 10453671]

[19] Oklund SA, Prolo DJ, Gutierrez RV, King SE. Quantitative comparisons of healing in cranial fresh autografts, frozen autografts and processed autografts, and allografts in canine skull defects. Clin Orthopaed Related Res 1986; (205): 269-91.

[http://dx.doi.org/10.1097/00003086-198604000-00034]

[20] Johansson B, Grepe A, Wannfors K, Hirsch JM. A clinical study of changes in the volume of bone grafts in the atrophic maxilla.
Dentomaxillofac Radiol 2001; 30(3): 157-61

[http://dx.doi.org/10.1038/sj.dmfr.4600601] [PMID: 11420628]

[21] Bystedt H, Rasmusson L. Porous titanium granules used as osteoconductive material for sinus floor augmentation: a clinical pilot study. Clin Implant Dent Relat Res 2009; 11(2): 101-5.

[http://dx.doi.org/10.1111/j.1708-8208.2008.00100.x] 18657154]

[22] Dursun E, Dursun CK, Eratalay K, Orhan K, Celik HH, Tözüm TF. Do porous titanium granule grafts affect bone microarchitecture at augmented maxillary sinus sites? A pilot split-mouth human study. Implant Dent 2015; 24(4): 427-33.

[http://dx.doi.org/10.1097/ID.0000000000000275] [PMID: 26200164]

[23] Verket A, Lyngstadaas SP, Rasmusson L, et al. Maxillary sinus augmentation with porous titanium granules: A microcomputed tomography and histologic evaluation of human biopsy specimens. Int J Oral Maxillofac Implants 2013; 28(3): 721-8.

[http://dx.doi.org/10.11607/jomi.2853] [PMID: 23748302]

(C) 2019 Arab et al.

This is an open access article distributed under the terms of the Creative Commons Attribution 4.0 International Public License (CC-BY 4.0), a copy of which is available at: (https://creativecommons.org/licenses/by/4.0/legalcode). This license permits unrestricted use, distribution, and reproduction in any medium, provided the original author and source are credited. 